\title{
Antioxidant Activity Of Platelet Rich Plasma Wistar Rats With Dpph And Abts Test
}

\author{
Wienaldi ${ }^{1}$, I Nyoman Ehrich Lister ${ }^{2 *}$, Bungaran Sihombing ${ }^{3}$ \\ 1,2,3 Faculty of Medicine, Universitas Prima Indonesia \\ *Corresponden Authors \\ Email: nyoman@unprimdn.ac.id
}

\begin{abstract}
.
Free radicals and reactive oxygen species (ROS) are the cause of diseases such as cancer, diabetes, cardiovascular and inflammatory. The presence of an increase in the number of free radicals and excess ROS production in the body can cause an imbalance of the immune system. Therefore, additional antioxidants are needed from outside the body. During this time there are several antioxidant synthesis drugs such as (Butyl Hydroxy Anisole) BHA and (Butyl Hydroxyl Toluene) BHT. But in its use, this drug causes side effects. Therefore, it is necessary to source antioxidants that have no side effects if consumed. PRP is a product produced from fresh whole blood that contains components of Red blood cells, White blood cells, Platelets, and Plasma. Plasma contains organic and inorganic molecules and ions wherein abundant conditions serve to transport other substances. To determine the ability of PRP as an antioxidant, fractionation, and bioactivity tests for free radical capture of 1,1-diphenyl-2-picrilhydrazil (DPPH) and color decay tests at 2,2'-azino-bis-[3-ethylbenzotiazolin sulfonate] (ABTS) in vivo.. Based on the results of this study, PRP has antioxidant activity that increases along with the decrease in THE concentration of PRP with an antioxidant activity value of $10.57 \%$ with the DPPH test and $5.85 \%$ with the ABTS test at the lowest concentration $(6.25 \mu \mathrm{g} / \mathrm{mL})$. IC50 averages $190.29 \mu \mathrm{g} / \mathrm{mL}$ with DPPH test and $126.60 \mu \mathrm{g} / \mathrm{mL}$ with the ABTS test. The results of this study are an indication that PRP can be used as a treatment therapy related to the anti-oxidant activity.
\end{abstract}

Keywords: antioxidant, DPPH, ABTS, platelet rich plasma

\section{INTRODUCTION}

The body's defense against side effect of chemical compounds such as free radicals occurs through the antioxidant system (Naito and Kasai 2015). Antioxidants can prevent the rate of damage due to free radicals because they can slow or prevent the oxidation process. The protection of antioxidants against blood plasma becomes an illustration of total protection against the body because all the body's cell metabolites will boil down to blood plasma. In addition, some metabolite products resulting from oxidation of radical compounds such as malonaldehyde (MDA) and conjugated diene are often used as models by researchers to describe the body's antioxidant defense system against free radical compounds (Cavallo et al. 2016).PRP as a biological product is produced from fresh whole blood and contains components of Red Blood Cells, White blood cells, Platelets, and Plasma. Plasma contains organic and inorganic molecules and ions wherein abundant conditions serve to transport other substances.

PRP is obtained by conducting a centrifugation process to obtain platelet-rich plasma. Platelet levels in PRP are 20 times more than in the blood and contain more protein. PRP can increase rate of proliferation because PRP has bioactive molecules known to be a growth factor in tissues (Martin-Sole et al. 2016; Rosadi et al. 2019; Salem, Helmi, and Assaf 2018). Platelets provide many growth factors (GFs) (Sonker et al., 2015). Platelet Rich Plasma (PRP) is a low-cost procedure for producing high concentration autologous GFs (Cavallo et al. 2016). Therapy with Platelet Rich Plasma can produce growth factors (Cavallo et al. 2016; Zhang, Wang, and Sun 2016). PRP autologous platelet concentration produces 3-5 times the concentration of platelets throughout the blood (El-Tahawy et al. 2017; Vokurka et al. 2016). However, the use of PRP for the improvement of health problems, especially in the pancreas is still very little. Before the application of PRP as an alternative treatment method of choice, it is necessary to research its ability in antioxidant activity because PRP is a relatively new approach in regenerative medicine and attracted a lot of attention over the past two 
decades (Pavlovic et al. 2016). Therefore, to find out its effect on antioxidants, further research is needed in vivo. This study aims to test the effects of platelet-rich plasma in increasing the antioxidant activity of blood plasma flavonoids.

\section{METHODS}

\section{Preparation of Platelet-rich Plasma (PRP)}

Platelet-rich Plasma (PRP) was prepared at PT. Aretha Medika Utama. The experimental animals used in this study were male Wistar rats, aged 2.5 - 3 months, bodyweight 180-220 grams, and healthy. The selection of rats as experimental animals based on the consideration that genetically, rats are similar to humans and can adapt to the laboratory environment. The initial stage of making PRP was anesthetized with Chloroform followed by surgery and taking 2-5 $\mathrm{ml}$ of rat blood from a puncture in the heart. A total of $3 \mathrm{ml}$ of blood was put into a purple tube with EDTA anticoagulant. The first centrifugation was carried out at a speed of $1600 \mathrm{rpm}$ for 10 minutes and produced three compartments in the blood with the bottom part being Erythrocytes, Buffy coat layer, and Plasma. Plasma was taken without crossing the Buffy coat limit and centrifuged again at $2000 \mathrm{rpm}$ for 10 minutes. This process will form 2 compartments, namely PPP and PRP. The PRP portion below is taken and mixed with $\mathrm{CaCl} 2$. After that, the $\mathrm{CaCl} 2$ precipitate above was removed so that PRP was obtained which was ready for use

\section{Antioxidant Analysis}

Antioxidant test using the ABTS method is calculated based on the loss of blue color due to the reduction of ABTS by antioxidants. The intensity of this blue color was measured at a wavelength of $745 \mathrm{~nm}$. PRP samples of $6.25 \mu \mathrm{g} / \mathrm{mL}, 12.50 \mu \mathrm{g} / \mathrm{mL}, 25.00 \mu \mathrm{g} / \mathrm{mL}, 50.00 \mu \mathrm{g} / \mathrm{mL}$, and $100.00 \mu \mathrm{g} / \mathrm{mL}$ were added to $2 \mu \mathrm{L}$ samples in a 96-well plate. ABTS working reagent was added as much as $198 \mu \mathrm{L}$ into the well containing the sample (well sample). In the well blank, $200 \mu \mathrm{L}$ of sample solvent (DMSO) was added. In the positive control, $200 \mu \mathrm{L}$ of ABTS working reagent was added. Plates were incubated for 6 minutes at $37{ }^{\circ} \mathrm{C}$. The absorbance was measured using a microplate reader at $=745 \mathrm{~nm}$. The DPPH Trapping Test was also carried out. A total of 200 $\mu \mathrm{L}$ of $0.077 \mathrm{mmol} \mathrm{DPPH}$ in DMSO was added to $50 \mu \mathrm{L}$ of the sample (on a microplate). The mixture was incubated at room temperature for 30 minutes and then the absorbance value was measured at a wavelength of $517 \mathrm{~nm}$ using a microplate reader. For the negative control, $250 \mu \mathrm{L}$ of DPPH was used, while for the blank, 250 $\mu \mathrm{L}$ of DMSO was used.

\section{Statistic Analysis}

The results of the data obtained were displayed as the mean \pm standard deviation (SD) of three repetitions of the data.

\section{RESULTS AND DISCUSSION}

Antioxidant test with DPPH (2,2-diphenyl-1-picryl-hydrazyl-hydrate)

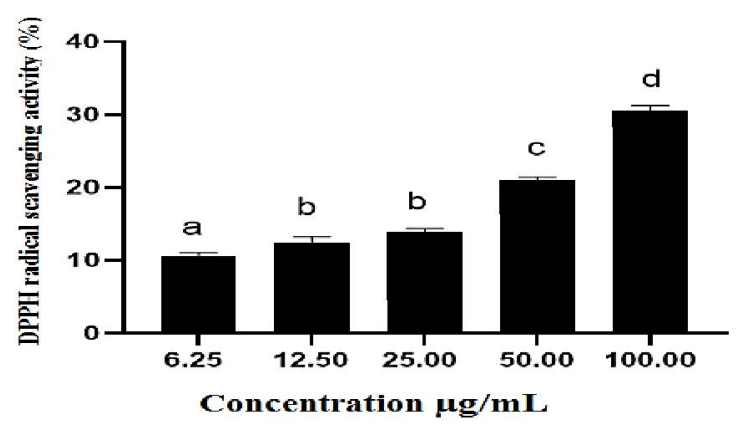

Fig 1. Effect of PRP on DPPH Antioxidant Activity

* Data are presented in mean \pm SD. Different superscript signs (a, b, c, d) show significant differences $(\mathrm{p}<0.05)$ Tukey HSD post hoc test. 
Based on the results in Fig. 1, it showed that the antioxidant activity of PRP on DPPH increased with decreasing PRP concentration. At the lowest concentration $(6.25 \mu \mathrm{g} / \mathrm{mL})$, PRP showed the highest antioxidant activity against DPPH trapping with a percent activity of $10.57 \%$. These results indicate that PRP has antioxidant activity against DPPH radicals. The results of PRP initially become a promising indication for therapy, such as insulin resistance in type 2 DM patients due to oxidative stress which plays a role in the pathogenesis of this disorder. Oxidant production exceeds antioxidant activity in cells and plasma which causes insulin receptor disturbances, especially in skeletal muscle. Oxidative stress is defined as a condition due to an imbalance between oxidants and antioxidants in the body (Sheikhpour 2013; Shradha and Sisodia 2010).

Table 1. IC 50 $_{0}$ DPPH Trapping Activities on PRP

\begin{tabular}{|c|l|l|c|}
\hline \multicolumn{1}{|c|}{ Sample } & \multicolumn{1}{|c|}{ Equality } & \multicolumn{1}{c|}{$\mathbf{R}_{\mathbf{2}}$} & $\mathbf{I C}_{\mathbf{5 0}}(\boldsymbol{\mu \mathbf { g }} \mathbf{\mathbf { m L }})$ \\
\hline PRP (1st repeated) & $\mathrm{y}=0.2167 \mathrm{x}+9.432$ & 0.99 & 187.21 \\
\hline PRP (2nd repeated) & $\mathrm{y}=0.2172 \mathrm{x}+9.2884$ & 0.99 & 187.44 \\
\hline PRP (3th repeated) & $\mathrm{y}=0.2057 \mathrm{x}+9.572$ & 0.98 & 196.50 \\
\hline Averange & $\mathrm{y}=0.2132 \mathrm{x}+9.4308$ & 0.99 & 190.29 \\
\hline
\end{tabular}

Based on Table 1, the antioxidant activity of Platelet-rich Plasma (PRP) in DPPH increased along with the decrease in the concentration of the extract. At the lowest concentration $(6.25 \mu \mathrm{g} / \mathrm{mL})$, PRP showed the highest antioxidant activity against DPPHtrapping with an average IC50 of $190.29 \mathrm{~g} / \mathrm{mL}$. The high antioxidant activity is thought to be because the polyphenol compounds in the ethanol extract produce strong activity in scavenging free radicals. Polyphenols or flavonoids directly contribute to the antioxidant effects. It's also has a role in preventing lipid oxidation (Sannigrahi, et al., 2010).

\section{Antioxidant test with ABTS (2,2'-Azinobis(3-Ethylbenzthiazoline-6-Sulfonate))}

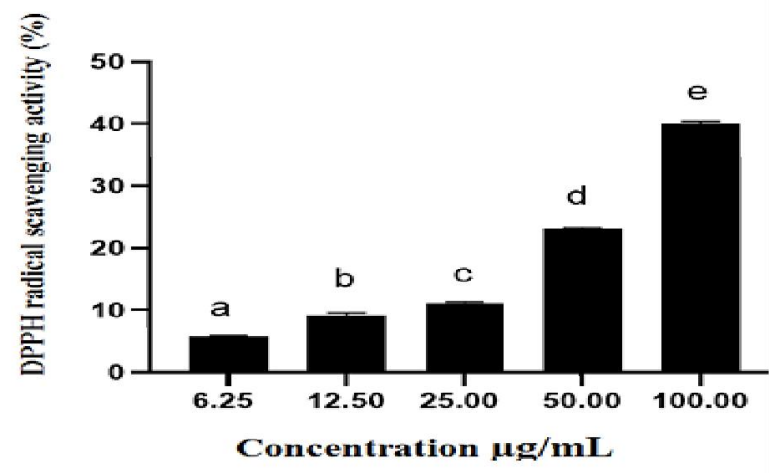

Fig 2. Effect of PRP on ABTS Antioxidant Activity

* Data are presented in mean \pm SD. Different superscript signs (a, b, c, d) show significant differences $(\mathrm{p}<0.05)$ Tukey HSD post hoc test.

Based on Fig.2, the antioxidant activity of PRP in ABTS increased along with the decrease in the concentration of the extract. At the lowest concentration $(6.25 \mu \mathrm{g} / \mathrm{mL})$, PRP showed the highest antioxidant activity against ABTS trapping with an activity percentage of $5.85 \%$. The above results indicate that PRP has antioxidant activity on ABTS radicals.

Tabel 2. $\mathrm{IC}_{50}$ ABTS Trapping Activities on PRP

\begin{tabular}{|c|l|l|c|}
\hline \multicolumn{1}{|c|}{ Sample } & \multicolumn{1}{|c|}{ Equality } & \multicolumn{1}{c|}{$\mathbf{R}_{\mathbf{2}}$} & $\mathbf{I C}_{\mathbf{5 0}}(\boldsymbol{\mu g} / \mathbf{m L})$ \\
\hline PRP (1st repeated) & $\mathrm{y}=0.3632 \mathrm{x}+3.6623$ & 0.99 & 127.90 \\
\hline PRP (2nd repeated) & $\mathrm{y}=0.3667 \mathrm{x}+3.8032$ & 0.99 & 125.98 \\
\hline PRP (3th repeated) & $\mathrm{y}=0.3673 \mathrm{x}+3.6413$ & 0.98 & 126.21 \\
\hline Averange & $\mathrm{y}=0.3657 \mathrm{x}+3.7023$ & 0.99 & 126.60 \\
\hline
\end{tabular}

Based on Table 2, the antioxidant activity of PRP in ABTS increased as the concentration of the extract decreased. At the lowest concentration $(6.25 \mu \mathrm{g} / \mathrm{mL})$, PRP showed the highest antioxidant activity 
against ABTS trapping with an average IC50 of $126.60 \mu \mathrm{g} / \mathrm{mL}$. The value of the correlation coefficient (R2) between the total antioxidant content and the free radical scavenging ability of PRP was quite high, namely 0.98 and 0.99 . This high value indicates a very strong linear relationship between the total antioxidant content in PRP and the free radical scavenging ability of DPPH and ABTS. The results of this study indicate that the antioxidant properties of PRP have a relationship with free radical scavenging and total antioxidants. Therefore, PRP is thought to contain a reductant and react with free radicals to become stable radicals and further terminate the radical chain reaction.

\section{CONCLUSION}

Based on the results of this study, PRP has an antioxidant activity that increases as the concentration of PRP decreases with an antioxidant activity value of $10.57 \%$ with the DPPH test and $5.85 \%$ with the ABTS test at the lowest concentration $(6.25 \mu \mathrm{g} / \mathrm{mL})$. The results of this study indicate that PRP become a promising product to treat various health problems.

\section{REFERENCES}

[1] Cavallo, Carola, Alice Roffi, Brunella Grigolo, Erminia Mariani, Loredana Pratelli, Giulia Merli, Elizaveta Kon, Maurilio Marcacci, and Giuseppe Filardo. 2016. "Platelet-Rich Plasma: The Choice of Activation Method Affects the Release of Bioactive Molecules.” BioMed Research International 2016.

[2] El-Tahawy, Nashwa Fathy, Rehab Ahmed Rifaai, E. A. al Saber, Saadia Ragab Saied, and Randa Ahmed Ibrahim. 2017. "Effect of Platelet Rich Plasma (Prp) Injection on the Endocrine Pancreas of the Experimentally Induced Diabetes in Male Albino Rats: A Histological and Immunohistochemical Study." J Diabetes Metab 8(730):2.

[3] Martin-Sole, Oriol, Joan Rodo, Lluis Garcia-Aparicio, Josep Blanch, Victoria Cusi, and Asteria Albert. 2016. "Effects of Platelet-Rich Plasma (PRP) on a Model of Renal Ischemia-Reperfusion in Rats." PLoS One 11(8):e0160703.

[4] Naito, Ryo, and Takatoshi Kasai. 2015. "Coronary Artery Disease in Type 2 Diabetes Mellitus: Recent Treatment Strategies and Future Perspectives.” World Journal of Cardiology 7(3):119.

[5] Pavlovic, Voja, Milan Ciric, Vladimir Jovanovic, and Predrag Stojanovic. 2016. "Platelet Rich Plasma: A Short Overview of Certain Bioactive Components." Open Medicine 11(1):242-47.

[6] Rosadi, Imam, Karina Karina, Iis Rosliana, Siti Sobariah, Irsyah Afini, Tias Widyastuti, and Anggraini Barlian. 2019. "In Vitro Study of Cartilage Tissue Engineering Using Human Adipose-Derived Stem Cells Induced by Platelet-Rich Plasma and Cultured on Silk Fibroin Scaffold.” Stem Cell Research \& Therapy 10(1):1-15.

[7] Salem, Neveen, Nawal Helmi, and Naglaa Assaf. 2018. "Renoprotective Effect of Platelet-Rich Plasma on CisplatinInduced Nephrotoxicity in Rats.” Oxidative Medicine and Cellular Longevity 2018.

[8] Sheikhpour, Robab. 2013. "Diabetes and Oxidative Stress: The Mechanism and Action." Iranian Journal of Diabetes and Obesity 5(1):40-45.

[9] Shradha, Bisht, and S. S. Sisodia. 2010. "Www. Ijrap. Net." International Journal of Research in Ayurveda \& Pharmacy 1(1):33-42.

[10] Vokurka, J., E. Gopfert, M. Blahutkova, E. Buchalova, and M. Faldyna. 2016. "Concentrations of Growth Factors in Platelet-Rich Plasma and Platelet-Rich Fibrin in a Rabbit Model.” Veterinární Medicína 61(10):567-70.

[11] Zhang, Zhenxiang, Yong Wang, and Junying Sun. 2016. "The Effect of Platelet-Rich Plasma on Arthroscopic Double-Row Rotator Cuff Repair: A Clinical Study with 12-Month Follow-Up." Acta Orthopaedica et Traumatologica Turcica 50(2):191. 